\title{
Effectiviness of Low Dose Aripiprazole in the Treatment of Austistic Child With Separation Anxiety Disorder
}

\begin{abstract}
Necati Uzun
Elazı̆̆ Psychiatry Hospital, Elazı̆̆, Turkey

\author{
Ömer Faruk Akça \\ Necmettin Erbakan University, Konya, Turkey
}

Autism Spectrum Disorder (ASD) is a neurodevelopmental disorder that begins in childhood, causes significant problems in communication and significantly affects daily functioning and quality of life of the individual. Many psychiatric disorders, such as anxiety disorders, ticdisorders, and attention deficit hyperactivity disorder may be comorbid with ASD. Atypical antipsychotics are frequently using the treatment of irritability and comorbid psychiatric disorders in individuals with ASD. Aripiprazole popularity has raised in recent years due to its efficacy profile. Effectiveness of low dose aripiprazole as monotherapy in the treatment of psychiatric disorders are remarkable. In this case report, we will present effectiveness of low dose aripiprazole monotherapy in the treatment of an autistic child with separation anxiety disorder and Tourette Syndrome.
\end{abstract}

Keywords: autism, anxiety disorders, aripiprazole, separation anxiety disorder

\section{Introduction}

Autism Spectrum Disorder (ASD) is a common disorder which effects children's development of language and social skills. About 1 in 68 children has been diagnosed with autism spectrum disorder acording to the Centers for Disease Control and Prevention (CDC) datas (Centers for Disease Control and Prevention (CDC), 2014). Psychiatric comorbidities are common in children with ASD. Anxiety disorders also shows high comorbidity in children with ASD (Van Steensel, Francisca, Bögels, \& Bruin, 2013).

Some guidlines recommend selective serotonin reuptake inhibitors (SSRIs) as first line treatment for anxiety disorders (Bandelow, Zohar, Hollander, Kasper, \& Möller, 2008). SSRIs are also effective in the treatment of autistic individuals with anxiety disorders (Alexander, Mathewson, \& Hollander, 2006). Use of atypical antipscyhotics to augment antianxiety medication has been shown to be beneficial in the treatment of anxiety (Rynn et al., 2011) As far as we know this is the first reported case of an autistic child with seperation anxiety disorder treated with low dose aripiprazole.

\section{Case Report}

The case presented here was a severn year-old boy consulted our clinic with complaints of can not staying alone, having an exessive fear in sleeping alone without his mother, and slight hyperactivity. He can not speak except few words, such as mother, father, and water. According to his mother, he had an exessive fear when she had gone away altough some close relatives with the side of him. In these situations, he had crying and hurting

\footnotetext{
Necati Uzun, consultant child and adolescent psychiatrist, Elazı̆̆ Psychiatry Hospital.

Ömer Faruk Akça, associate professor, Department of Child and Adolescent Psychiatry, Meram School of Medicine, Necmettin Erbakan University.
} 
himself. The patient was diagnosed as having ASD and seperation anxiety disorder according to Diagnostic and Statistical Manual of Mental Disorders (5th ed.) (American Psychiatric Association, 2013). Clinical Global Index (CGI) score of anxiety symptoms was seven at the begining of treatment. Aripiprazole $2.5 \mathrm{mg}$ /day was initiated and two weeks later, anxiety symptoms slight improved and CGI score was five at this visit. Aripiprazole doze increased to $5 \mathrm{mg}$ /day and one month later the patient's anxiety symptoms had decreased, and his CGI score was one and his hyperactivite was also improved and anxiety symptoms never recurred over two months of follow-up.

\section{Discussion}

Treatment of anxiety with SSRIs is wellknown. Some studies showed the beneficial results of augmentation of therapeutic effect of SSRIs by adding an aripiprazole in the treatment of obsessive compulsive disease (OCD) and depression (Akyol-Ardic et al., 2016; Sugawara, Sakamoto, Harada, Shimizu, \& Ishigooka, 2016). Also aripiprazole monotherapy effective in the treatment of OCD (Connor, Payne, Gadde, Zhang, \& Davidson, 2005). Low dose aripiprazole brought about improvement in anxiety symptoms in our case.

Future studies investigating the antipscyotic monotheraphy on anxiety disorders will improve our knowledge of this topic.

\section{References}

Akyol-Ardic, U., Ercan, E. S., Kutlu, A., Yuce, M., Ipci, M., \& Inci, S. B. (2016). Successful Treatment Response with Aripiprazole Augmentation of SSRIs in Refractory Obsessive-Compulsive Disorder in Childhood. Child Psychiatry \& Human Development, 48(5), 699-704.

Alexander, K., Mathewson, K. A., \& Hollander, E. (2006). Selective serotonin reuptake inhibitors in autism: A review of efficacy and tolerability. The Journal of clinical psychiatry, 67(3), 407-414.

American Psychiatric Association. (2013). Diagnostic and statistical manual of mental disorders (5th ed.). Arlington, VA: American Psychiatric Publishing.

Bandelow, B., Zohar, J., Hollander, E., Kasper, S., \& Möller, H. (2008). World Federation of Societies of Biological Psychiatry (WFSBP) guidelines for the pharmacological treatment of anxiety, obsessive-compulsive and post-traumatic stress disorders-first revision. The World Journal of Biological Psychiatry, 9 (4), 248-312.

Centers for Disease Control and Prevention (CDC). (2014). CDC estimates 1 in 68 children has been identified with autism spectrum disorder. Retrieved from https://www.cdc.gov/media/releases/2014/p0327-autism-spectrum-disorder.html

Connor, K. M., Payne, V. M., Gadde, K. M., Zhang, W., \& Davidson, J. R. (2005). The use of aripiprazole in obsessive-compulsive disorder: Preliminary observations in 8 patients. The Journal of clinical psychiatry, 66(1), 49-51.

Rynn, M., Puliafico, A., Heleniak, C., Rikhi, P., Ghalib, K., \& Vidair, H. (2011). Advances in pharmacotherapy for pediatric anxiety disorders. Depression and anxiety, 28(1), 76-87.

Sugawara, H., Sakamoto, K., Harada, T., Shimizu, S., \& Ishigooka, J. (2016). A retrospective study of predictive factors for effective aripiprazole augmentation of antidepressant therapy in treatment-resistant depression. Neuropsychiatric disease and treatment, 12, 1151-1156.

Van Steensel, F. J. A., Francisca, J. A., Bögels, S. M., \& Bruin, E. (2013). Psychiatric comorbidity in children with autism spectrum disorders: A comparison with children with ADHD. Journal of Child and Family Studies, 22(3), 368-376. 